\title{
Os Direitos Humanos e as contradições na titulação das terras das comunidades quilombolas do Tocantins ${ }^{1}$
}

\author{
Derechos Humanos y contradicciones en la titulación de tierras de las \\ comunidades quilombolas en Tocantins
}

\author{
Human righths and contradictions in land titling of quilombola \\ communities in Tocantins
}

\author{
Paulo Sérgio Gomes Soares ${ }^{2}$ \\ Pedro Alexandre Conceição Aires Gonçalves ${ }^{3}$
}

\begin{abstract}
Resumo
O objetivo do artigo é realizar uma análise da situação das comunidades quilombolas do estado do Tocantins pelas contradições evidenciadas nas dificuldades de materialização do direito ao território tradicional previsto na Constituição Federal de 1988 e em instrumentos normativos de Direito Internacional. A partir de uma perspectiva crítica, o debate expõe a forma como o campo antropológico e o jurídico se inter-relacionam para garantir os direitos constitucionais e materialização dos Direitos Humanos em franca contradição com os interesses das elites rurais brasileiras e expansão do agronegócio, fator que expõe as contradições, também, no campo jurídico entre os interesses individuais e o coletivos, bem como as tensões enfrentadas pelos remanescentes das comunidades quilombolas na luta pela titulação de suas terras. O estudo identifica e analisa a partir dos princípios constitucionais - a atuação de instituições como a Defensoria Pública, Ministério Público e Poder Judiciário do estado do Tocantins frente aos conflitos decorrentes das disputas territoriais envolvendo tais interesses.
\end{abstract}

Palavras-Chave: Direitos Humanos. Comunidades Quilombolas. Regularização Fundiária. Agronegócio.

Resumen

El objetivo del artículo es realizar un análisis de la situación de las comunidades quilombolas en el estado de Tocantins debido a las contradicciones evidenciadas en las dificultades para materializar el derecho al territorio tradicional previsto en la Constitución Federal de 1988 y en los instrumentos normativos del derecho internacional. Desde una perspectiva crítica, el debate expone cómo los campos antropológicos y legales están interrelacionados para garantizar los derechos constitucionales y la materialización de los derechos humanos en abierta contradicción con los intereses de las élites rurales brasileñas y la expansión de los agronegocios, un factor que También expone las contradicciones en el campo legal entre los intereses individuales y colectivos, así como las tensiones que enfrentan los restos de las comunidades quilombolas en la lucha por la titulación de sus tierras. El estudio identifica y analiza, con base en principios constitucionales, el desempeño de instituciones como la Oficina del Defensor Público, la Fiscalía y el Poder Judicial del Estado de Tocantins ante los conflictos derivados de disputas territoriales que involucran tales intereses.

Palabras-Claves: Derechos Humanos. Comunidades Quilombola. Regularización de tierras. Agronegocio.

Abstract

\footnotetext{
${ }^{1}$ Artigo apresentado no II Congresso Internacional Online de Estudos sobre Culturas, na modalidade online, 2020.

${ }^{2}$ Doutor em Educação; Universidade Federal do Tocantins; Palmas, Tocantins, Brasil; psoares@uft.edu.br

${ }^{3}$ Mestrando no Programa de Pós-Graduação Mestrado Profissional em Prestação Jurisdicional e Direitos Humanos; Universidade Federal do Tocantins; Palmas, Tocantins, Brasil; pedroairesg@gmail.com
} 
The objective of the article is to carry out an analysis of the situation of quilombola communities in the state of Tocantins due to the contradictions evidenced in the difficulties of materializing the right to the traditional territory provided for in the Federal Constitution of 1988 and in normative instruments of international law. From a critical perspective, the debate exposes how the anthropological and legal fields are interrelated to guarantee constitutional rights and the materialization of human rights in open contradiction with the interests of Brazilian rural elites and the expansion of agribusiness, a factor that it exposes the contradictions, also, in the legal field between individual and collective interests, as well as the tensions faced by the remnants of quilombola communities in the struggle for the titling of their lands. The study identifies and analyzes - based on constitutional principles - the performance of institutions such as the Public Defender's Office, the Public Ministry and the Judiciary of the State of Tocantins in the face of conflicts arising from territorial disputes involving such interests.

Keywords: Human rights. Quilombola Communities. Land regularization. Agribusiness.

\section{Introdução: as contradições que ferem os Direitos Humanos}

Atualmente, o Brasil está passando por momentos turbulentos e tensos com implicações políticas e sociais nefastas para os povos tradicionais, sobretudo devido à ascensão de grupos de extrema direita ao poder, determinando políticas que excluem os Direitos Humanos destes povos, já que não lhes garante o direito à terra e inviabiliza os debates sobre a possibilidade de demarcação de seus territórios, no caso das comunidades indígenas, e titulação, no caso das comunidades quilombolas, que estão garantidos na Constituição Federal de 1988. O avanço do capital internacional, exigindo o monopólio das terras agricultáveis e a prioridade na exploração dos recursos naturais do país, tem gerado conflitos e revelado as profundas contradições entre o que garante a Carta Magna para os povos tradicionais e o que defendem elites (sobretudo agrárias) em prol de seus interesses.

Diante desse quadro, o debate jurídico e antropológico é fundamental para equacionar as demandas das comunidades tradicionais, tendo em vista que o direito à terra depende do reconhecimento de suas singularidades culturais e modos de vida vinculados a ela. Notadamente, os grupos de extrema direita negam não somente um direito à terra garantido constitucionalmente, negam também a condição de existência das comunidades tradicionais ao não reconhecerem suas identidades próprias e suas singularidades socioculturais, como recentemente assistimos estarrecidos ao ministro da educação, que nada tem a ver com as políticas relacionadas à terra, posicionar-se, em reunião ministerial, com a seguinte frase: “Odeio o termo 'povos indígenas', odeio esse termo. Odeio. O 'povo cigano'. Só tem um povo nesse país. Quer, quer. Não quer, sai de ré. É povo brasileiro, só tem um povo. Pode ser preto, pode ser branco, pode ser japonês, pode ser descendente de índio, mas tem que ser brasileiro, pô! Acabar com esse negócio de povos e privilégios" (FALCÃO; VIVAS, G1, 2020). 
Assim têm se pronunciado os apoiadores do chamado "gabinete do ódio", que não respeitam as diferenças por desconhecerem a diversidade cultural do país, tratando os direitos constitucionalmente garantidos aos povos tradicionais como privilégios. A primeira contradição surge dessa negação que, em si, revela a negação da própria Constituição Federal que rege o país em relação aos Direitos Humanos.

A mídia internacional tem mostrado a invasão das terras indígenas na Amazônia, a derrubada desenfreada da floresta e a anistia dos crimes ambientais, bem como o avanço do agronegócio e da mineração ilegal. A mídia tem mostrado a luta dos povos indígenas e o assassinato de suas lideranças, mas pouco tem mostrado a luta dos quilombolas e a invasão de suas terras, que também tem contornos dramáticos frente à expansão das fronteiras agrícolas.

O relatório do Comitê da Associação Brasileira de Antropologia (ABA), que monitora as tensões em torno das terras quilombolas, trouxe à tona um quadro com os nomes das lideranças quilombolas que foram executadas no Brasil, em 2016 e 2017.

Segundo dados da Coordenação Nacional de Articulação das Comunidades Negras Rurais Quilombolas (CONAQ) em 201414 líderes quilombolas foram assassinados. Estima-se que aproximadamente 70 lideranças quilombolas estejam ameaçadas de morte hoje no Brasil. A chacina em Iúna fez com que o estado da Bahia concentrasse mais de 70\% dos assassinatos de quilombolas em 2017. Nos dois anos do golpe (2016/2017) já são 131 mortos. (MOMBELLI; COSTA FILHO, s/d, p. 15).

Estamos assistindo aos massacres das comunidades em estreita relação com a pressão econômica por exploração dos recursos naturais nos territórios, fator que tende a acirrar as tensões e a violência em função da expansão do agronegócio. As políticas de acesso à terra não possuem nenhum sentido se não estiverem de acordo com o que determina a chamada "bancada ruralista", que representa os interesses das elites agrárias no poder. Diante dessa conjuntura, observa-se que a busca por satisfazer os interesses individuais, conforme a lógica da mercantilização da terra, tem produzido retrocessos nos Direitos Humanos, atingindo frontalmente os povos tradicionais e o meio ambiente. Essa é a segunda contradição - entre o que defende o discurso falacioso de "equilíbrio" entre produção e sustentabilidade e o que, de fato, tem produzido, no revés, a destruição social e ambiental.

A terceira contradição é uma consequência das duas anteriores, advém da insegurança jurídica provocada por esse cenário que fragiliza o papel das instituições e acaba gerando a ausência dos serviços públicos para e nas comunidades, bem como a perversa omissão do Poder Público em relação à efetividade da justiça em prol das demandas coletivas. A Constituição de 1988 protege interesses que estão para além dos meramente individuais e confere legitimidade aos interesses coletivos. "Uma visão comunitarista da liberdade positiva 
limita e condiciona em prol do coletivo a esfera da autonomia individual" (XIMENES, 2010, p. 57) e, nesse caso, as comunidades quilombolas estão respaldadas pela Carta Magna, já que a expressão das liberdades individuais, organizadas em interesses coletivos, fundamentam os direitos positivados.

O artigo que ora se apresenta, faz parte das pesquisas em curso no Programa de PósGraduação Mestrado Profissional em Prestação Jurisdicional e Direitos Humanos e tem como fulcro mostrar as contradições existentes entre os direitos coletivos previstos na Constituição Federal de 1988 e os direitos individuais, defendidos como um direito à propriedade privada, num contexto de expansão do capitalismo sobre o monopólio das terras, produzindo como efeito a violência contra os povos tradicionais, que dependem do Poder Público para demarcar e/ou titular as suas terras e acabar com os conflitos.

\section{A história e as reminiscências como fundamentos dos Direitos Humanos}

Hoje, segundo a Fundação Cultural Palmares (FCP), o Brasil possui aproximadamente 3.000 comunidades quilombolas e no estado do Tocantins, estão certificadas 45 delas, que atendem a prerrogativa de reminiscências históricas e de ancestralidade em relação à terra. A FCP define tais comunidades da seguinte forma: "Quilombolas são descendentes de africanos escravizados que mantém tradições culturais, de subsistência e religiosas ao longo dos séculos". Angola, Congo, Benguela, Monjolo, Senegâmbia, Cabinda, Mina e Rebolo, são antigos territórios africanos de onde milhares de pessoas foram sequestradas e trazidas ao Brasil como mercadorias. Escravos. Coisificados. Desumanizados e padecendo de toda sorte de exploração, encontraram na fuga e, às vezes, nos enfretamentos com seus senhorios e autoridades estatais constituídas, a alternativa de vida viável.

O Decreto $n^{\circ} .4 .887 / 2003$, no artigo $2^{\circ}$, que regulamentou o texto constitucional de 1988, definiu as comunidades quilombolas da seguinte forma.

Consideram-se remanescentes das comunidades dos quilombos os grupos étnicosraciais, segundo critérios de auto atribuição, com trajetória histórica própria, dotados de relações territoriais específicas, com presunção de ancestralidade negra relacionada com resistência à opressão histórica sofrida.

Os quilombos são movimentos negros de resistência que se formaram desde os primeiros tempos da colônia por pessoas que fugiram e se opuseram à opressão de proprietários das lavouras e das minas. Os quilombolas agrupados em regiões de difícil acesso 
representaram a oposição do povo negro ao arbítrio e à força do estado escravocrata (TRECCANI, 2019), criando e mantendo características socioculturais próprias que foram transmitidas ao longo das gerações.O quilombo traz consigo as suas próprias características de organização e de luta por espaço conquistado e mantido ao longo das gerações (LEITE, 2000), de modo que a sua história, seus festejos, crenças religiosas, linguagens e expressões, formas de organização, ligação com a terra, etc., perfazem suas singularidades, as bases antropológicas que fundamentam os seus direitos.

A política de reconhecimento dos 'remanescentes das comunidades dos quilombos', expressa na Constituição Brasileira de 1988, introduz um relevante debate para aqueles que se interessam por uma reflexão crítica sobre os limites e as possibilidades de interlocução entre o conhecimento jurídico e o conhecimento antropológico no contexto em que ambos estão voltados à defesa dos grupos sociais que contam com garantias constitucionais. Nesse contexto, o desafio que se apresenta à prática antropológica fundamenta-se em produzir uma problematização das próprias categorias jurídicas que foram concebidas com um caráter genérico. (CHAGAS, 2001, p. 211).

A relação com a terra guarda o fulcro das questões relacionadas à manutenção da comunidade, ao mesmo tempo em que documenta a história e as reminiscências dos povos africanos escravizados no Brasil. $\mathrm{O}$ artigo 216, inciso V, da Constituição diz o seguinte: " $§ 5^{\circ}$ Ficam tombados os documentos e os sítios detentores de reminiscências históricas dos antigos quilombos". Assim, a história e as reminiscências são os fundamentos legais para os Direitos Humanos, se aceitarmos a premissa de que o direito à terra das comunidades tradicionais é parte dos Direitos Humanos que garantem a existência das singularidades socioculturais e manutenção da vida para as novas gerações.

Diante dessa perspectiva, é fundamental compreender o quilombo como um conceito socioantropológico, sobretudo devido às implicações políticas e jurídicas que advém no esteio da luta pela titulação das terras. Os laudos antropológicos do Instituto Nacional de Colonização e Reforma Agrária (INCRA) constituem relatórios que justificam e dão suporte ao direito à terra, são os chamados Relatório Técnico de Identificação e Delimitação (RTID), construídos com o auxílio das comunidades, que expõem os hábitos e costumes, trajetórias históricas e relações com a terra para compor as peças técnicas.

O Decreto $n^{\circ} .4 .887 / 2003$, art. $2^{\circ}$, diz o seguinte: $\S 3^{\circ}$ Para a medição e demarcação das terras, serão levados em consideração critérios de territorialidade indicados pelos remanescentes das comunidades dos quilombos, sendo facultado à comunidade interessada apresentar as peças técnicas para a instrução procedimental. Então, nesse momento histórico 
de tensão em que desponta um projeto de nação contraditório e exclusivo, faz-se necessário que os povos tradicionais reivindiquem com mais intensidade os seus direitos positivados.

Desde a abolição da escravatura, em 1888, e a Proclamação da República, em 1889, os quilombos têm se constituído em movimentos de resistência, embora continuem segregados e alijados de qualquer processo inclusivo na sociedade brasileira (RIBEIRO, 2015). De fato, a escravidão negra no Brasil, ao longo de quase quatro séculos, deixou marcas que, ainda hoje,estão longe de cicatrizar. O regime escravocrata e a posterior omissão do estado e da sociedade brasileira culminaram num quadro de grande desigualdade e, consequentemente, de profunda injustiça, cujos reflexos estão cada vez mais avivados pelo racismo estrutural escondido atrás do mito da democracia racial.

Diante desse contexto, a Constituição de 1988, numa perspectiva multicultural, pluriétnica e reparatória, passou a prever, de forma expressa, a proteção das comunidades quilombolas e de seu território tradicionalmente ocupado. Buscou-se tanto a proteção dos integrantes dessas comunidades, que não raro encontram-se em situação de vulnerabilidade, bem como a tutela de um direito transindividual, a saber, o patrimônio cultural imaterial consistente na preservação das tradições, modos de vida e costumes, elementos componentes da identidade nacional (MARGRAF; OLIVEIRA, 2017).

A Lei n’. 12.288/2010, garante o seguinte, na Seção III - Da Cultura: “Art. 18. É assegurado aos remanescentes das comunidades dos quilombos o direito à preservação de seus usos, costumes, tradições e manifestos religiosos, sob a proteção do Estado". No caso dessas comunidades, o que aduz o art.1 ${ }^{\circ}$, III, da Constituição Federal: "III - a dignidade da pessoa humana" - a dignidade só pode ser materializada através do reconhecimento dos valores que consolidaram os vínculos indissociáveis com a terra, sendo fundamentais para que se preserve o patrimônio imaterial das comunidades. As tradições, de um ponto de vista antropológico, asseguram que eles reivindiquem a terra para a manutenção da existência digna das novas gerações e, de um ponto de vista jurídico, sustentem os interesses coletivos como direitos positivados.

\section{A contradição entre os Direitos Humanos e o avanço do agronegócio nas regiões do MATOPIBA}

Além da Constituição brasileira, a garantia ao território tradicional é matéria tutelada pelo Direito Internacional dos Direitos Humanos. A jurisprudência da Corte Interamericana de Direitos Humanos acolheu o entendimento de que o art. 21 da Convenção Americana, 
sobre direito à propriedade privada, também protege o direito dos povos nativos à propriedade das terras que tradicionalmente ocupam.

Em essência, nos termos do artigo 21 da Convenção, os estados devem respeitar a relação especial que os membros dos povos indígenas e tribais têm com seu território, de modo a garantir a sua sobrevivência social, cultural e econômica. Tal proteção da propriedade, nos termos do art. 21 da Convenção, em conjugação com os artigos 1.1 e 2 do mesmo artigo, atribuído aos estados uma obrigação positiva de tomar medidas especiais para garantir aos povos indígenas e integrantes tribais o exercício pleno e igualitário do direito aos territórios que estejam ocupando tradicionalmente.

No âmbito global do sistema de proteção aos Direitos Humanos, a Convenção Internacional $\mathrm{n}^{\circ} .169$ da Organização Internacional do Trabalho (OIT) sobre povos indígenas e tribais, aprovada pelo Congresso Nacional mediante o Decreto Legislativo ${ }^{\circ}$. 143, de 20 de junho de 2002, promulgada pelo Decreto $\mathrm{n}^{\circ}$. 5.051, em 19 de abril de 2004, defende a garantia por parte dos Estados da proteção territorial dos povos tradicionais, levando em consideração o vínculo espiritual, cultural, afetivo que as comunidades exercem com os seus territórios. Pelo decreto: "1. Os governos deverão assumir a responsabilidade de desenvolver, com a participação dos povos interessados, uma ação coordenada e sistemática com vistas a proteger os direitos desses povos e a garantir o respeito pela sua integridade.”

Entretanto, passados mais de trinta anos da promulgação da nossa carta constitucional e dezoito anos da internalização da Convenção $\mathrm{n}^{\circ}$. 169 da OIT, é bastante tímida a evolução na efetivação dos direitos das comunidades tradicionais, incluindo as comunidades quilombolas.

Cabe ressaltar o que diz o artigo 68, do Ato das Disposições Constitucionais Transitórias (ADCT), na Constituição de 1988, onde consta o direito das comunidades quilombolas a propriedade das terras que tradicionalmente ocupam, cabendo ao Poder Público emitir os títulos correspondentes. Conforme segue: "aos remanescentes das comunidades dos quilombos que estejam ocupando suas terras é reconhecida a propriedade definitiva, devendo o Estado emitir-lhes os títulos respectivos”. Porém, observa-se que, na prática, a efetividade constitucional é irrelevante, tornando-se necessário investigar os problemas e as contradições que envolvem o tema e expor caminhos possíveis no atendimento às demandas, conforme o que determina a Carta Magna e conforme se exige da prestação jurisdicional.

Dentre as 45 comunidades quilombolas do Tocantins que foram certificadas pela FCP, ainda não se tem notícia da finalização do processo de reconhecimento territorial de nenhuma das áreas dessas comunidades. Vale notar o quadro abaixo, elaborado por Pinheiro e 
Soares (2019, p. 192): Quadro: nomes das comunidades quilombolas e sua localização nos municípios do Tocantins:

\begin{tabular}{|c|c|c|}
\hline Municípios & Denominação das Comunidades & $\mathrm{N}^{\circ}$. de Comunidades \\
\hline Almas & Baião e Poço Dantas & 2 \\
\hline Aragominas & Projeto da Baviera e Pé do Morro & 2 \\
\hline Araguatins & Ilha São Vicente & 1 \\
\hline Arraias & $\begin{array}{l}\text { Lagoa da Pedra, Fazenda Lagoa dos patos e } \\
\text { Fazendas Káagados }\end{array}$ & 3 \\
\hline Arraias/Paranã & Mimoso & 1 \\
\hline Brejinho de Nazaré & $\begin{array}{l}\text { Córrego Fundo, Malhadinha, Curralinho } \\
\text { do Pontal e Manoel João }\end{array}$ & 4 \\
\hline Chapada da Natividade & São José e Chapada da Natividade & 2 \\
\hline Conceição do Tocantins & Água Branca e Matões & 2 \\
\hline Dianópolis & Lajeado & 1 \\
\hline Dois Irmãos do Tocantins & Santa Maria das Mangueiras & 1 \\
\hline Esperantina & Carrapiché, Ciríaco e Praiachata & 3 \\
\hline Filadélfia & Grotão & 1 \\
\hline Jaú do Tocantins & Rio das Almas & 1 \\
\hline $\begin{array}{l}\text { Lagoa do Tocantins/Novo } \\
\text { Acordo/Santa Tereza do } \\
\text { Tocantins }\end{array}$ & Barra do Aroeira & 1 \\
\hline Mateiros & $\begin{array}{l}\text { Mumbuca, Ambrósio, Carrapato, Formiga, } \\
\text { Margens do Rio Novo, Riachão, Rio Preto } \\
\text { e Boa Esperança }\end{array}$ & 8 \\
\hline Monte do Carmo & Mata Grande & 1 \\
\hline Muricilândia & Dona Juscelina & 1 \\
\hline Natividade & Redenção & 1 \\
\hline Paranã & Claro, Ouro Fino e Prata & 3 \\
\hline Ponte Alta do Tocantins & Lagoa Azul & 1 \\
\hline Porto Alegre do Tocantins & São Joaquim e Laginha & 2 \\
\hline Santa Fé do Araguaia & Cocalinho & 1 \\
\hline Santa Rosa do Tocantins & Morro de São João & 1 \\
\hline São Félix do Tocantins & Povoado do Prata & 1 \\
\hline
\end{tabular}

Fonte: Pinheiro e Soares (2019), com base nas Certidões Expedidas às Comunidades Remanescentes de Quilombos (CRQs) pela FCP, atualizada conforme Portaria n ${ }^{\circ}$. 122/2018 e publicada no DOU em 26/04/2018.

A morosidade da União, por intermédio do INCRA, na efetivação dos procedimentos de regularização territorial, e, ainda, a omissão injustificável do estado do Tocantins, por meio de seu Instituto de Terras (ITERTINS), em realizar a regularização fundiária dessas comunidades, contribuem para o cenário de disputa territorial e conflitos no campo.

De outro lado, o acesso a serviços públicos básicos ainda é obstado à maioria dos quilombos contemporâneos. Com efeito, em visita aos quilombos para trabalhos rotineiros de prestação jurisdicional, não é incomum encontrar comunidades sem acesso a serviços de água tratada e energia elétrica. Políticas de saneamento básico e atendimentos de saúde ainda são 
incipientes. $\mathrm{O}$ acesso à educação também é precário, sendo bastante corriqueiro encontrar crianças e adolescentes se deslocando por vários quilômetros até uma escola que, por vezes, não possui as condições mínimas para o processo educacional.

Diante desse cenário, percebe-se que o atendimento dos mandamentos constitucionais insculpidos na Carta de 1988 ainda está longe de ocorrer de forma plena. A conjugação de insegurança jurídica envolvendo os territórios quilombolas e a grave omissão de serviços públicos essenciais, provoca um processo velado de expulsão dos integrantes das comunidades de seus territórios tradicionais. A perversa omissão do Poder Público em relação às questões quilombolas tem como consequência a violação de direitos das comunidades tradicionais, reduzindo a possibilidade de exercício digno da cidadania de seus integrantes.

Em diferentes partes do Brasil, sobretudo após a Abolição (1888), os negros têm sido desqualificados e os lugares em que habitam são ignorados pelo poder público ou mesmo questionados por outros grupos recém-chegados, com maior poder e legitimidade junto ao estado (LEITE, 2000, p. 334).

A ausência de políticas públicas, de acordo com o modelo constitucional, termina por render ensejo à continuidade da histórica política etnocida, antinegro e antiquilombola, coisificadorade sujeitos, excludente e injusta, num momento histórico de pandemia da COVID- 19, que tem revelado a pobreza e o racismo estrutural, seja nas comunidades tradicionais seja nas comunidades urbanas - as favelas - onde não há acesso, muitas vezes, nem a água encanada. Há, ainda, manifestações no Rio de Janeiro, devido a morte de crianças assassinadas por policiais e, nos EUA, contra o racismo, após a morte de um homem negro por um policial branco. No Brasil, começa a se desenhar um cenário de luta da população negra contra o racismo e contra a necropolítica do estado autoritário e violento.

O pano de fundo da violência e da omissão estatal no estado do Tocantins pode ser creditado às políticas de fomento à expansão do agronegócio, que desconhece e desconsidera o contexto de existência das comunidades que habitam tradicionalmente os territórios do estado, criando um ambiente de tensão entre os interesses privados e os interesses coletivos das comunidades.

Com efeito, nos últimos 40 anos, a descoberta tecnológica de que as planícies do cerrado oferecem condições muito favoráveis ao cultivo da soja, desde que corrigida a acidez do solo, despertou a cobiça das elites agrárias, dando origem aos conflitos com as comunidades tradicionais. Iniciativas como a do Programa de Desenvolvimento Agropecuário do Maranhão, Tocantins, Piauí e Bahia (PDA MATOPIBA), em que não há qualquer previsão 
de consideração das comunidades quilombolas em sua implantação, tornam o cenário futuro ainda mais incerto.

A experiência da Defensoria Pública do estado do Tocantins na defesa das comunidades quilombolas tem indicado que tais problemas ainda estão longe de melhores resultados. Segundo os relatórios expedido pelo Núcleo da Defensoria Pública Agrária do estado do Tocantins, nenhuma das comunidades certificadas pela Fundação Palmares teve a regularização de seu território, e, em razão disso, a maior parte delas enfrenta tensões territoriais contra fazendeiros criadores de gado (comum na região do Bico do Papagaio e Sudeste do Tocantins), sojicultores (região central do Estado) e mineradores (região Sul e Sudeste do Tocantins).

A estrutura fundiária brasileira, que se reproduz no Tocantins, é caracterizada pela concentração de terras e oriunda de um processo histórico marcado por disputas pela propriedade, apresenta deficiências e distorções que prejudicam o pleno desenvolvimento em no país de uma política agrária justa, baseada na equidade e na justiça social.

No entanto, mesmo ciente de tais circunstâncias, o Sistema de Justiça (Poder Judiciário, Ministério Público, Defensoria Pública e Ordem dos Advogados do Brasil) ainda não conseguem apresentar respostas para os conflitos fundiários, em grande medida, devido à situação de incerteza e insegurança jurídica. Consequentemente, tende a se acirrarem os conflitos que vão demandar a atuação da Defensoria Pública e do Poder Judiciário. Segundo a Comissão Pastoral da Terra (2018), em 2018, foram registrados 38 conflitos por terra no estado Tocantins, atingindo 1574 famílias. Dentre os conflitos, ao menos 9 se deram em territórios reivindicados por comunidades quilombolas.

Assim, parece ser necessária uma imediata mudança de perspectiva do Poder Público (incluindo o Sistema de Justiça), a fim de que as normas constitucionais protetivas deixem de ser meros discursos e se tornem, de fato, garantias concretas do exercício da cidadania das comunidades, conforme determina a Constituição Federal.

\section{Referências}

BRASIL.Constituição da República Federativa do Brasil de 1988. Disponível em: http://www.planalto.gov.br/ccivil_03/Constituicao/Constituicao.htm Acesso em 04/01/2020.

. Decreto $n^{o} .4 .887$, de 20 de novembro de 2003. Regulamenta o procedimento para identificação, reconhecimento, delimitação, demarcação e titulação das terras ocupadas por remanescentes das comunidades dos quilombos de que trata o art. 68 do Ato das Disposições Constitucionais Transitórias. Disponível em: http://www.planalto.gov.br/ccivil_03/decreto/2003/D4887.htm Acesso em 04/01/2020. 
BRASIL. Decreto $n^{\circ}$. 5.051, de 19 de abril de 2004. Promulga a Convenção no 169 da Organização Internacional do Trabalho - OIT sobre Povos Indígenas e Tribais. Presidência da República Casa Civil Subchefia para Assuntos Jurídicos. Disponível em: file://C:/Users/User/Downloads/ci1.pdf Acesso em 24/05/2020.

Lei $n^{o}$. 12.288, de 20 de julho de 2010. Institui o Estatuto da Igualdade Racial. Disponível em: http://www.planalto.gov.br/ccivil_03/_Ato2007-2010/2010/Lei/L12288.htm Acesso em 04/01/2020.

Ministério da Cultura. Fundação Cultural Palmares. Comunidades Remanescentes de Quilombos. Disponível em: http://www.palmares.gov.br/?page_id=37551 Acesso em: 02 jul. 2018.

BRASIL. Instituto Nacional de Colonização e Reforma Agrária (INCRA). Disponível em: http://www.incra.gov.br/pt/ acesso em 24/05/2020.

CHAGAS, M. F. A política do reconhecimento dos "remanescentes das comunidades dos quilombos". Horizontes Antropológicos, Porto Alegre, ano 7, $\mathrm{n}^{\circ}$. 15,pp. 209-235, julho de 2001. ISSN: 0104-7183. Disponível em: https://www.scielo.br/pdf/ha/v7n15/v7n15a09.pdf Acesso em 12/01/2020. (Artigo em periódico digital).

COMISSÃO INTERAMERICANA DE DIREITOS HUMANOS. Estatuto da Corte Interamericana de Direitos Humanos. Aprovada pela resolução AG/RES. 448 (IX-O/79), adotado pela Assembleia Geral da OEA, em seu Nono Período Ordinário de Sessões, realizado em La Paz, Bolívia, outubro de 1979. Disponível em: https://www.cidh.oas.org/basicos/portugues/v.Estatuto.Corte.htm Acesso em 25/05/2020.

COMISSÃO PASTORAL DA TERRA. Caderno de Conflitos do Campo 2018. Disponível em:https://www.cptnacional.org.br/component/jdownloads/send/41-conflitos-no-campobrasil-publicacao/14154-conflitos-no-campo-brasil-2018?Itemid=0 Acesso em 24/9/2019.

FALCÃO, M.; VIVAS, F. MPF pede explicações a Weintraub por críticas às expressões 'povos indígenas' e 'povo cigano'.TV Globo - Brasília26/05/2020, 21h04. Portal G1 Política. Disponível em: https://g1.globo.com/politica/noticia/2020/05/26/mpf-pedeexplicacoes-a-weintraub-por-declaracoes-sobre-termos-povos-indigenas-e-povocigano.ghtmlAcesso em: 25/05/2020

LEITE, I. B. Os quilombos no Brasil: questões conceituais e normativas. Etnográfica. UFSC, Vol. IV (2), pp. 333-354, 2000. ISSN:0873-6561 Disponível em: http://ceas.iscte.pt/etnografica/docs/vol_04/N2/Vol_iv_N2_333-354.pdf Acesso em 15/01/2020. (Artigo em periódico digital).

MARGRAF, A. F.; OLIVEIRA, P. S. Quilombos Brasileiros: Constitucionalismo Contemporâneo e Políticas Públicas em Defesa dos Remanescentes de Quilombolas. Rio de Janeiro: Lumen Juris, 2019.(Obra completa)

MOMBELli, R.; COSTA FILHO, A. (Coord.). Relatório de Atividades do Comitê Quilombos (2017-2018). Associação Brasileira de Antropologia - ABA. Disponível em:http://www.aba.abant.org.br/files/20190320_5c926e768042f.pdfAcesso em 03/05/2020. 

05/09/2019.

RIBEIRO, Darcy. O Povo Brasileiro. São Paulo: Global, 2015. (Obra completa)

SOARES, P. S. G.; OLIVEIRA, G. P. T. C; PINHEIRO, A. S. Direitos Humanos e direito à terra: a situação jurídica das comunidades quilombolas tocantinenses. Humanidades \& Inovação. V. 6, n . 17,pp. 189-203, 2019. ISSN: 2358-8322. Disponível em:

file:///C:/Users/User/Desktop/Artigos\%20publicados/Artigo\%20Humanidades\%20e\%20Inova ção\%206816-2-10-20191204.pdf Acesso em: 10/01/2020. (Artigo em periódico digital).

TRECCANI, G D. et all. Manual de Direito Agrário Constitucional: lições de Direito Agroambiental. Belo Horizonte: Fórum, 2019. (Obra Completa)

XIMENES, J. M. O Comunitarismo \& a dinâmica do controle concentrado de Constitucionalidade. Rio de Janeiro: Lúmen Júris, 2010. (Obra Completa) 